\title{
ANTIBACTERIAL ACTIVITY OF ISOLATED ENDOPHYTIC FUNGI FROM RAUVOLFIA SERPENTINA (L.) BENTH. EX KURZ
}

\author{
RAJSHREE SAHU, SUNEEL KUMAR, RAVINDRA PRASAD AHARWAL, SARDUL SINGH SANDHU* \\ Fungal Biotechnology and Invertebrate Pathology Laboratory, Department of Biological Sciences, Rani Durgavati University, Jabalpur \\ 482001, Madhya Pradesh, India \\ Email: ssandhu@rediffmail.com
}

Received: 30 Oct 2015 Revised and Accepted: 09 Sep 2016

\begin{abstract}
Objective: The aim of the present study was to isolate the endophytic fungi from medicinal plant Rauvolfia serpentina (L.) Benth. ex Kurz. (Family Apocynaceae) and observed their antibacterial activity against bacteria as well as the molecular characterization of most potent fungal strain

Methods: Collection and isolation of endophytic fungi from different parts (root, shoot, leaves) of Rauvolfia serpentina plant. Screening of endophytic fungi for antibacterial activity was scrutinised against six bacteria viz. Bacillus subtilis, Enterococcus sp., Klebsiella pneumoniae, Escherichia coli, Salmonella typhimurium and Streptococcus pyogenes by using Agar well diffusion method. For molecular sequencing of potent fungi, the DNA was extracted, quantified and amplified by using two oligonucleotide primers ITS4 and ITS6 in PCR.

Results: A total seven endophytic fungi Aspergillus niger, Penicillium citrinum, Cladosporium sp., Curvularia lunata, Aspergillus sp., Alternaria sp. and Aspergillus fumigatus were isolated from different parts of Rauvolfia serpentina and fungal strain Penicillium citrinum was shown the maximum zone of inhibition against Bacillus subtilis $(23.0 \pm 0.12 \mathrm{~mm})$, Escherichia coli $(19.9 \pm 0.16 \mathrm{~mm})$, Streptococcus pyrogens $(19.2 \pm 0.59 \mathrm{~mm})$, Enterococcus sp., $(17.2 \pm 0.08 \mathrm{~mm})$, Klebsiella pneumoniae $(18.9 \pm 0.16 \mathrm{~mm})$ and Salmonella typhimurium $(15.1 \pm 0.16 \mathrm{~mm})$. The molecular sequencing of the potent fungi was done by primers (ITS4 and ITS6) which showed strong specificity with fungal DNA and the percentages of identical matches of ITS4 and ITS6 DNA sequences in the GeneBank database (NCBI) were determined to $98 \%$.
\end{abstract}

Conclusion: In the present study, the endophytic fungal strain Penicillium citrinum showed the potential source of antibacterial bioactive compounds and molecular sequencing of this fungus helps in future to determine the various metabolic pathways that are responsible for the production of such type of novel compounds.

Keywords: Antibacterial activity, Colonization Frequency, Bioactive Compounds, Hyphae, Reserpine

(C) 2016 The Authors. Published by Innovare Academic Sciences Pvt Ltd. This is an open access article under the CC BY license (http://creativecommons. org/licenses/by/4. 0/) DOI: http://dx.doi.org/10.22159/ijpps.2016v8i11.9733

\section{INTRODUCTION}

Endophytic fungi are the most important part of biodiversity and beneficial for the survival of other organisms. Endophytes play an essential role in ecological processes that includes mutualism, parasitism and commensalism [1-3]. These are symbiotic microorganisms, which live internal tissue of the plant body without causing any negative effects in the host plants [4]. The reproductions in endophytic fungi take place by spores and vegetative growth showing the formation of conidia and hyphae [5]. These are found in different parts of host plant like leaves, petioles, stem, twigs, bark, root, fruit, flower and seeds [1]. Generally, endophytic fungi are classified into different classes based on their host range, colonisation in plants and type of tissue colonised, diversity of plants, transmission and fitness benefits [6]. Endophytic fungi are produced a number of active novel bioactive compounds like alkaloids, peptides, steroids, terpenoids, phenols, quinines and flavonoids which are beneficial in agriculture, industries and in pharmaceutical industries for the production of medicine, drugs and natural biochemical's those provide protection against pathogenic organisms $[7,8]$.

Sandhu et al. [9] isolated the endophytic fungi from Calotropis procera (Linn.) R. Br. plant of Jabalpur region and tested their antibacterial activity against Escherichia coli, Klebsiella pneumoniae, Streptococcus pyogenes, Salmonella typhi, Bacillus subtilis and Enterococcus sp. The endophytic fungi Trametes hirsute produce podophyllotoxin and other related aryl tetralin lignans bioactive compounds which used against cancer [10]. In other research work Sandhu et al. [11] also isolated the endophytic fungi Aspergillus fumigatus, Aspergillus niger, Fusarium solani, Aspergillus repens, Alternaria alternata, Alternaria sp., Phoma hedericola and Fusarium oxysporum from Menthe viridis and observed their antibacterial activity against the test bacterial strain and also optimized various parameters for maximum production of antibacterial bioactive compounds.

In the present work endophytic fungi were isolated from the medicinal plant Rauvolfia serpentina also known as Sarpagandha. It is perennial woody rootstock plant commonly found all over the Indian subcontinent and South East Asian countries. More than 80 types of alkaloids are isolated from Rauvolfia species like reserpine [12]. The bioactive compounds isolated from Rauvolfia serpentina used in a number of treatments like insomnia, hypotonic, sedative, sexual aggression, anti-hypertensive and in cardiovascular diseases. Therefore, the present study was to isolated, identified and screening of antibacterial activity of endophytic fungi isolated from different parts of Rauvolfia serpentina.

\section{MATERIALS AND METHODS}

\section{Collection of plant sample}

Different parts of medicinal plant Rauvolfia serpentina (L.) Benth. ex Kurz. (root, stem and leaves) were chosen for isolation of endophytic fungi. The sample was collected from plant nursery of Jawaharlal Nehru Krishi Vishwa Vidyalaya (JNKVV) Jabalpur (M. P.). The research work was conducted during February to March 2015.

\section{Isolation of endophytic fungi}

Isolation of endophytic fungi was carried out by methods described by Petrini [13] with some modification. The plant material was rinsed gently in tap water to remove dust and debris. Then the plant samples were cut into small fragments. Each sample was surface disinfection with $70 \%$ ethanol for $1 \mathrm{~min}$ and immersed in sodium hypochlorite $(\mathrm{NaOCl})$ for $30 \mathrm{~s}$ and then rinsed in sterile distilled 
water for $1 \mathrm{~min}$. The sample pieces were blotted on dry sterilized Whatman filter paper no. 1 . After proper drying, 4 segments of plant sample were transferred on PDA plate which supplemented with an antibiotic (Amoxicillin). Plates were incubated at $26 \pm 1^{\circ} \mathrm{C}$ for 6 to $7 \mathrm{~d}$. Pure colonies of endophytic fungi appearing from the edge of the segments were transferred to PDA slants and preserved at $4{ }^{\circ} \mathrm{C}$ for further study.

\section{Calculation of colonising frequency}

Colonization frequency (CF\%) was calculated as described by Suryanarayanan et al. [14] and Photita et al. [15]. Colonization frequency (\%) of an endophyte species was equal to the number of segments colonised by a single endophyte divided by the total number of segments observed x 100 .

Colonizing Frequency \%

$$
=\frac{\text { Number of segment colonized by fungi }}{\text { Total number of segment }} \times 100
$$

Morphological and molecular identification of isolated fungal strain

\section{Morphological identification}

Endophytic fungi isolated from $R$. serpentina were identified by using slide culture technique [16]. Morphological identification of endophytic fungi was done on the basis of their macroscopic and microscopic features such as colour, shape and growth of cultured colonies and the generated data was compared with available literature.

\section{Molecular identification of potential fungi}

\section{Isolation of DNA}

According to Sandhu, [17] total genomic DNA from the fungi was isolated by LETS buffer (Lithium chloride-EDTA-Tris $\mathrm{HCl}$ and
Sodium dodecyl sulphate). A conical flask with $50 \mathrm{ml}$ PDB media was inoculated with a loop full of conidia and incubated for 6 to $7 \mathrm{~d}$. Then the mycelia was harvested, washed with distilled water and hand pressed for removal of excess water from the mycelia, dried with filter papers and treated with liquid nitrogen, further crushed in a pastel-motor by adding $0.7 \mathrm{ml}$ LETS \{LETS $(0.1 \mathrm{M} \mathrm{LiCl}, 10 \mathrm{Mm}$ EDTA, $10 \mathrm{Mm} \mathrm{HCl}$ and $p \mathrm{H} \mathrm{8)}$ and $0.5 \%$ SDS $\}$ extraction buffer. The crushed mycelia were poured in the centrifuge tubes and vortexed for few min and centrifuged at $5000 \mathrm{rpm}$ for $10 \mathrm{~min}$. After centrifugation, the supernatant was transferred into another sterilised tube, and the pellet was discarded. One ml of phenol: chloroform: isoamyl alcohol (25:24:1) was administered in the tubes and vortexed for $1 \mathrm{~min}$ at medium speed. It was centrifuged at $10000 \mathrm{rpm}$ in a centrifuge for $10 \mathrm{~min}$. Two distinct layers were formed in the centrifuge tube one aqueous layer and another organic phase. The aqueous layer was transferred in other sterilised tube, and $70 \%$ chilled absolute ethanol was added to the sample and kept on ice for $15 \mathrm{~min}$. After that, spinned for $15 \mathrm{~min}$ in a microcentrifuge at $4{ }^{\circ} \mathrm{C}$ at $10000 \mathrm{rpm}$ for $10 \mathrm{~min}$. The supernatant was removed, and the pellet was dried by inverting the tubes gently and washed with $70 \%$ ethanol. The pellet was preserved in nuclease free water for future use.

\section{Quantification and PCR amplification of isolated DNA [18, 19]}

The quantity of the isolated DNA was checked in UV-VIS spectrophotometer. From the stock $1 \mu \mathrm{l}$, DNA was mixed with $49 \mu \mathrm{l}$ sterilised distilled water to get 50 times dilution. The A260/280 was recorded to check the purity of DNA. PCR amplification of ITS region was done in $20 \mu \mathrm{l}$ of reaction mixture containing PCR buffer, 1X (Kappa, SA); $\mathrm{MgCl}_{2}, 3 \mathrm{mmol}$; dNTP mix, $0.25 \mathrm{mmol}$; Taq DNA polymerase, $0.05 \mathrm{U}$; primer, 1 picomol and template DNA, $50 \mathrm{ng}$. Sterilised nuclease free water was used as negative control. The oligonucleotide primers used for PCR amplification was ITS4 and ITS6 as depicted in table 1. Thirty-five cycles of PCR were performed by using denaturation at $94{ }^{\circ} \mathrm{C}$ for $10 \mathrm{~s}$ annealing at $48^{\circ} \mathrm{C}$ for $30 \mathrm{~s}$, followed by extension $72{ }^{\circ} \mathrm{C}$ for $6 \mathrm{~min}$.

Table 1: Primers used for PCR amplification

\begin{tabular}{|c|c|c|c|c|c|}
\hline Oligonucleotide & Sequences (5'-3') & GC \% & Tm Value & Length & Product size \\
\hline ITS 4 & TCC TCC GCT TAT TGA TAT G & 50 & $51.0^{\circ} \mathrm{C}$ & 19 & $700 \mathrm{bp}$ \\
\hline ITS 6 & GAA GGT GAA GTC GTA ACA AGG & 60 & $56.0^{\circ} \mathrm{C}$ & 21 & \\
\hline
\end{tabular}

\section{Source of bacteria strain}

The six pathogenic bacteria strain Bacillus subtillis, Streptococcus pyogenes, Escherichia coli, Klebsiella pneumoniae, Salmonella typhimurium and Enterococcus sp. was provided by the Fungal Biotechnology and Invertebrate Pathology Laboratory (FBIPL), RDVV, Jabalpur (M. P.). Bacterial cultures were maintained on nutrient agar medium slant (NAM) and incubated at $37^{\circ} \mathrm{C}$ for $24 \mathrm{~h}$ in the bacterial incubator and stored at $4{ }^{\circ} \mathrm{C}$ for preservation.

\section{Mass production of secondary metabolites [20]}

For mass production of a secondary metabolite from endophytic fungi, $250 \mathrm{ml}$ of Potato dextrose broth (PDB) was prepared in 500 $\mathrm{ml}$ flasks. The medium was autoclaved at $121{ }^{\circ} \mathrm{C}$ and after that inoculated with various fungal cultures and incubated at $26 \pm 1{ }^{\circ} \mathrm{C}$ in the fungal incubator for $7^{\text {th }} 14^{\text {th }}$ and $21^{\text {st }}$ days. After respective days of inoculation $(7,14$ and $21 \mathrm{~d}$ ) the crude extract of the culture broth was filtered by using Whatman filter paper no.1 and observed their antibacterial activity against test bacteria.

\section{Screening of endophytic fungi}

The antibacterial activity of endophytic fungi was observed by using Agar well diffusion method [21] against six pathogenic bacteria. In this method, $25 \mu \mathrm{l}$ of bacterial suspension was spread over the nutrient agar medium plates and allowed to diffuse. The well was made aseptically in the plates with the help of cork borer (8 $\mathrm{mm}$ in diameter), and $80 \mu \mathrm{l}$ of metabolites was introduced into the well. Then the plates were incubated in the bacterial incubator at $37^{\circ} \mathrm{C}$ for $24 \mathrm{~h}$. Finally, antibacterial activity was resolute by measuring the diameter of zone of inhibition by using Hi-Media Antibiotic zone scale.

\section{RESULTS}

\section{Isolation of endophytic fungi}

In the present study, seven endophytic fungi were isolated from the different parts (viz. leaf, stem and root) of the R. serpentina collected from plant nursery of Jawaharlal Nehru Krishi Vishwavidyalaya (JNKVV) Jabalpur M. P. (India) as depicted in table 2. A total 32 segments (leaf 16, stem 8 and root 8) of $R$. serpentina were processed for the isolation of endophytic fungi.

Table 2: List of endophytic fungi isolated from $R$. serpentina

\begin{tabular}{lll}
\hline Plant part & Name of endophytic fungi & Class \\
\hline Leaf & Aspergillus niger & Eurotiomycetes \\
Leaf & Penicillium citrinum & Eurotiomycetes \\
Leaf & Cladosporium sp. & Dothideomycetes \\
Leaf & Curvularia lunata & Euascomycetes \\
Stem & Aspergillus sp. & Eurotiomycetes \\
Stem & Alternaria sp. & Dothideomycetes \\
Root & Aspergillus fumigatus & Eurotiomycetes \\
\hline
\end{tabular}


Table 3: Colonization frequency (\%) of isolated endophytic fungi

\begin{tabular}{lll}
\hline Plant parts & Name of endophytic fungi & \% frequency of colonization \\
\hline Leaf & Aspergillus niger & $12.25 \%$ \\
Leaf & Penicillium citrinum & $6.25 \%$ \\
Leaf & Cladosporium sp. & $12.50 \%$ \\
Leaf & Curvularia lunata & $18.75 \%$ \\
Stem & Aspergillus sp. & $12.50 \%$ \\
Stem & Alternaria sp. & $25.00 \%$ \\
Root & Aspergillus fumigatus & $37.50 \%$ \\
\hline
\end{tabular}

\section{Identification of isolated fungi}

\section{Morphological identification of endophytic fungi}

The fungal isolates were purified on PDA plates and identified on the basis of their morphological criterion that includes colonies on plates, the morphology of spore, hyphae and color. Based on a morphological feature they were identified as Aspergillus niger, Penicillium citrinum, Cladosporium sp., Curvularia lunata, Aspergillus sp., Alternaria sp. and Aspergillus fumigatus as shown in table 3.

\section{Molecular identification of potent fungi}

For the molecular identification both the designed oligonucleotide primers ITS4 (TCC TCC GCT TAT TGA TAT G) and ITS6 (GAA GGT GAA GTC GTA ACA AGG) show strong specificity for fungal DNA sequences. Using BLAST (NCBI), the percentages of identical matches of ITS4 and ITS6 DNA sequences in the Gene Bank database (NCBI) were determined to $98 \%$. This result was obtained by giving denaturation $94{ }^{\circ} \mathrm{C}$ for $30 \mathrm{~s}$, annealing $48{ }^{\circ} \mathrm{C}$ for $30 \mathrm{~s}$ and final extension for processing of DNA amplification was given $72{ }^{\circ} \mathrm{C}$ for 6 min. The molecular sequence of Penicilium citrinum is:

CGGGACGGCAGCGGTAAATACTGCGGAGACATTACCGAGTGCGGGCCCC TCGGGGCCCAACCTCCCACCCGTGTTGCCCGAACCTATGTTGCCTCGGC GGGCCCCGCGCCCGCCGACGGCCCCCCTGAACGCTGTCTGAAGTTGCAG TCTGAGACCTATAACGAAATTAGTTAAAACTTTCAACAACGGATCTCT TGGTTCCGGCATCGATGAAGAACGCAGCGAAATGCGATAACTAATGTG AATTGCAGAATTCAGTGAATCATCGAGTCTTTGAACGCACATTGCGCCC TCTGGTATTCCGGAGGGCATGCCTGTCCGAGCGTCATTGCTGCCCTCAA GCCCGGCTTGTGTGTTGGGCCCCGTCCCCCCCGCCGGGGGGACGGGCCC GAAAGGCAGCGGCGGCACCGCGTCCGGTCCTCAAGCGTATGGGGCTTCG TCACCCGCTATAGTAGGCCCGGCCGGCGACAGCCGACCCCCAACCTTTA ATTATCTCAAGTTGACCTCAGATCAGGTAGGAATAACCGCC

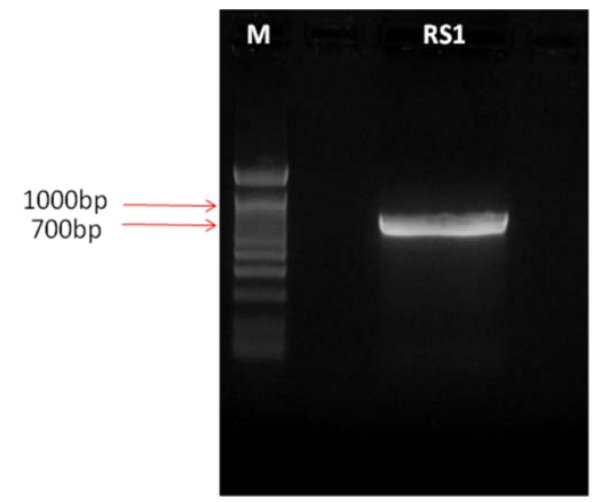

Fig. 1: 1\% Agarose gel data showing the band of amplified DNA (700bp)

\section{Detection of antibacterial activity}

To detect the antibacterial activity of metabolites extracted from the endophytic fungi were examined after $7^{\text {th }}, 14^{\text {th }}$ and $21^{\text {st }}$ days by Agar well diffusion method against six pathogenic bacteria. The antibacterial assay was carried out in triplicates. From the isolated endophytic fungal strain Penicillium citrinum was showed maximum zone of inhibition against $B$. subtilis $(23.0 \pm 0.12 \mathrm{~mm}), E$. coli $(19.9 \pm 0.16 \mathrm{~mm}), S$. pyogenes $(19.2 \pm 0.59 \mathrm{~mm})$, Enterococcus sp. $(17.2 \pm 0.08 \mathrm{~mm})$, K. pneumoniae $(18.9 \pm 0.16 \mathrm{~mm})$ and S. typhimurium $(15.01 \pm 0.16 \mathrm{~mm})$ as well as the positive control (Streptomycin) showed the zone of bacterial inhibition ranging from $15.46 \pm 0.15$ $\mathrm{mm}$ to $21.20 \pm 0.59 \mathrm{~mm}$ shown in table 4 .

Table 4: Antibacterial activity of isolated fungal strain

\begin{tabular}{|c|c|c|c|c|c|c|}
\hline \multirow[t]{2}{*}{ Name of fungal isolates } & \multicolumn{6}{|c|}{ Zone of inhibition (in mm) } \\
\hline & E. coli & B. subtilis & Enterococcus sp. & S. pyogenes & K. pneumonaie & S. typhimurium \\
\hline F. sp. & - & - & - & $12.0 \pm 0.10$ & $13.1 \pm 0.30$ & - \\
\hline A. sp. & $05.0 \pm 0.12$ & - & $18.0 \pm 0.2$ & $15.1 \pm 0.25$ & $17.3 \pm 0.36$ & $16.0 \pm 0.20$ \\
\hline C. sp. & $14.0 \pm 0.21$ & $10.9 \pm 0.20$ & - & - & $14.0 \pm 0.12$ & - \\
\hline C. lunata & - & $14.4 \pm 0.46$ & - & - & $14.9 \pm 0.16$ & $16.1 \pm 0.16$ \\
\hline Asp. sp. & - & - & - & - & - & - \\
\hline P. citrinum & $19.9 \pm 0.16$ & $23.0 \pm 0.12$ & $17.2 \pm 0.08$ & $17.2 \pm 0.15$ & $18.9 \pm 0.16$ & $15.1 \pm 0.16$ \\
\hline N. sp. & - & - & - & - & $05.0 \pm 0.12$ & - \\
\hline Streptomycin (1 mg/ml) & $16.1 \pm 0.11$ & $19.2 \pm 0.10$ & $15.4 \pm 0.15$ & $21.2 \pm 0.59$ & $17.4 \pm 0.10$ & $18.4 \pm 0.58$ \\
\hline
\end{tabular}

*Each value in the table is represented as mean $\pm \mathrm{SD}(\mathrm{n}=3)$. F. sp.: Fusarium sp., A. sp.: Alternaria sp., C. sp.: Cladosporium sp., C. lunata: Curvularia lunata; Asp. sp.: Aspergillus sp., P. citrinum: Penicillium citrinum and $N$. sp.: Nigrospora sp.

\section{Broad-spectrum activity of endophytic fungi}

For the broad-spectrum activity of endophytic fungi against 6 pathogenic bacterial strains are shown in table 5 and fig. 2 . Penicillium citrinum showed a maximum zone of inhibition against $E$. coli $(19.2 \pm 0.30 \mathrm{~mm})$, B. subtilis $(23.0 \pm 0.10 \mathrm{~mm})$, Enterococcus $\mathrm{sp}$. $(17.3 \pm 0.20 \mathrm{~mm}), S$. pyogenes $(19.3 \pm 0.15 \mathrm{~mm}), K$. pneumonaie
$(18.4 \pm 0.32 \mathrm{~mm})$ and S. typhimurium $(15.6 \pm 0.45 \mathrm{~mm})$. Similarly, Alternaria sp. was also showed a zone of inhibition against Enterococcus sp. $(18.2 \pm 0.25 \mathrm{~mm}), S$. pyogenes $(15.1 \pm 0.25 \mathrm{~mm}), K$. pneumoniae (17.6 $\pm 0.58 \mathrm{~mm}), S$. typhimurium and $(16.8 \pm 0.80 \mathrm{~mm}), E$. coli $(05.7 \pm 00.43 \mathrm{~mm})$. In the case of Curvularia lunata it showed antibacterial activity against $B$. subtilis $(13.5 \pm 0.30 \mathrm{~mm}), K$. pneumoniae $(15.7 \pm 1.07 \mathrm{~mm})$ and S. typhimurium $(16.7 \pm 0.32 \mathrm{~mm})$. 
Table 5: Broad-spectrum activity of selected endophytic fungi

\begin{tabular}{|c|c|c|c|c|c|c|}
\hline \multirow[t]{2}{*}{ Endophytic fungi } & \multicolumn{6}{|c|}{ Zone of inhibition (in mm) } \\
\hline & E. coli & B. subtilis & Enterococcus sp. & S. pyogenes & K. pneumoniae & S. typhimurium \\
\hline Alternaria sp. & $05.7 \pm 0.43$ & - & $18.2 \pm 0.25$ & $15.1 \pm 0.40$ & $17.6 \pm 0.58$ & $16.8 \pm 0.80$ \\
\hline Curvularia lunata & - & $13.5 \pm 0.30$ & - & - & $15.7 \pm 1.07$ & $16.7 \pm 0.32$ \\
\hline Penicillium citrinum & $19.02 \pm 0.30$ & $23.0 \pm 0.10$ & $17.3 \pm 0.20$ & $19.3 \pm 0.15$ & $18.4 \pm 0.32$ & $15.6 \pm 0.45$ \\
\hline
\end{tabular}

*Each value in the table is represented as mean $\pm S D(n=3)$.

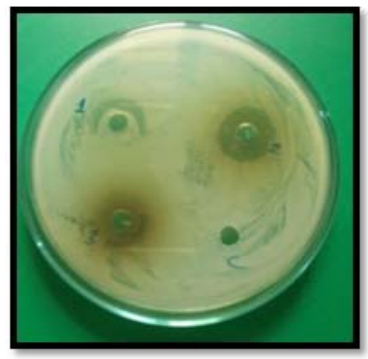

S. typhimurium

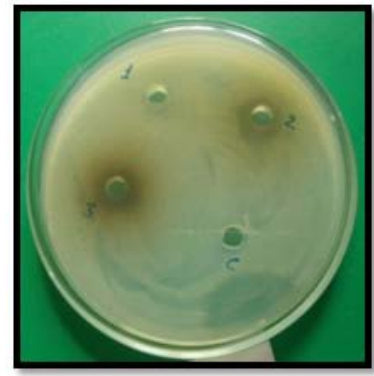

E. coli

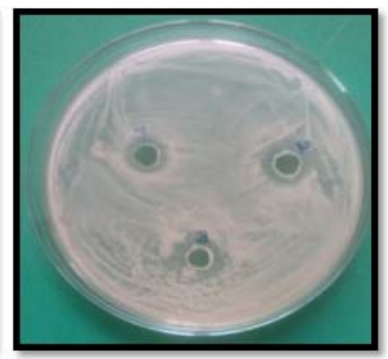

Enterococcus sp.

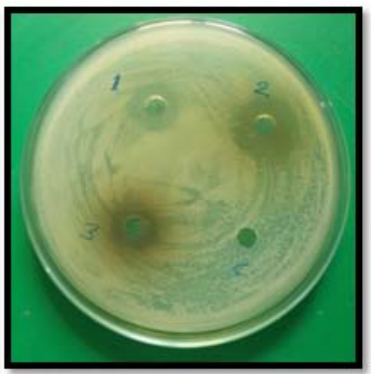

S. pyogenes

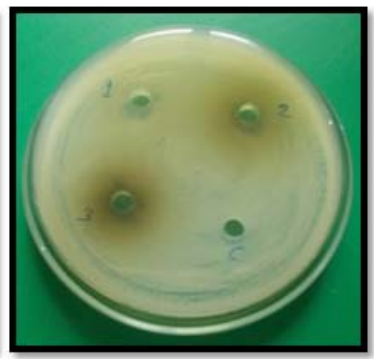

K. pneumoniae

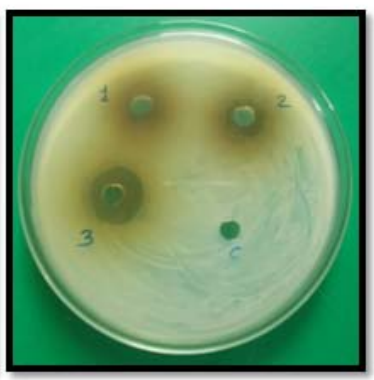

B. subtilis

Fig. 2: Antibacterial activities in endophytic fungi

\section{DISCUSSION}

The seclusion of endophytic fungi from medicinal plant produces a number of bioactive compounds, which have a therapeutic value. Therefore, in the present work endophytic fungi were isolated from the medicinal plant $R$. serpentina and observed their antibacterial against six pathogenic bacteria. The endophytic isolated Penicilium citrinum was displayed the best result against all the test strains. Similar, result was observed by Sandhu et al. [20] isolated the endophytic fungi from Saraca indica and detect their antibacterial activity against pathogenic bacteria and pointed to these endophytic fungi have the capability to produce a number of antibacterial bioactive compounds of multiple uses. Shekhawat et al. [22] were also isolated 35 endophytic fungi from leaves, the root of Melia azadirichta L. and observed their antibacterial activity against test strains. The endophytic fungi Aspergillus fumigatus, Aspergillus japonicas, Aspergillus niger, Fusarium semitectum, Curvularia pallescens, Phoma hedericola, Alternaria tenuissima, Fusarium solani, Drechslera australien and Aspergillus repens isolated from the medicinal plant Ricinus communis (L.) plant and observe their antibacterial activity against pathogenic bacteria [23]. Previous research worker had examined the production of the anti-leukemic and anti-tumor drug taxol from the endophytic fungi like Taxomyces andreanae and Pestalotiopsis microspora of Taxus spp. [24, 25].

The molecular identification of Penicillium citrinum was also done by using oligonucleotide primer for easy identification and comparison of molecular characteristics of the fungi with other organisms. Silva et al. [26] also identified the different strain of Aspergillus species on the basis of their morphological as well as molecular characteristics. Nyongesa et al. [27] isolated the Aspergillus species from the maize kernel and soil of maize field of Nandi County and identified on the basis of macroscopic and microscopic morphological characteristics.

\section{ACKNOWLEDGEMENT}

The authors wish to thank the Vice Chancellor of R. D. University, Jabalpur, India and the Head of the Department of Biological Science, R. D. University Prof. Y. K. Bansal for providing laboratory facility for this project.

\section{CONFLICT OF INTERESTS}

The authors have no potential conflict of interest regarding publication of the said manuscript.

\section{REFERENCES}

1. Arnold AE. Understanding the diversity of foliar endophytic fungi: progress, challenges and practise. Fungal Biol Rev 2007;21:51-6.

2. Saikkonen K, Faeth SH, Helander $M$, Sullivan TJ. Fungal endophytes: a continuum of interaction with host plants. Annu Rev Ecol Syst 1998;29:319-43.

3. Sieber T. Endophytic fungi in forest trees: are they mutualists? Fungal Biol Rev 2007;21:75-89.

4. Idris AM, Tahir, Idris E. Antibacterial activity of endophytic fungi extracts from the medicinal plant Kigelia africana. Egypt Acad J Biol Sci 2013;5:1-9.

5. Selosse MA, Schardl CL. Fungal endophytes of grass: hybrids rescued by vertical transmission? An evolutionary prospective. New Phytol 2007;173:452-8.

6. Rodriguez RJ, White JF, Arnold AE. Fungal endophytes: diversity and functional role. New Phytol 2009;182:314-30.

7. Tan RX, Zou WX. Endophytes: a rich source of functional metabolites. Nat Prod Rep 2001;18:448-59.

8. Sandhu SS, Kumar S, Aharwal RP, Kumar S. Isolation and detection of anti-bacterial activity of endophytic fungi from 
Bombex cebia and Argemone mexicana. J Chem Pharm Res 2014;6:95-100.

9. Sandhu SS, Aharwal RP, Kumar S. Isolation and antibacterial property of endophytic fungi isolated from Indian medicinal plant Calotropis procera (Linn.) R. Br. World J Pharm Pharm Sci 2014;3:678-91.

10. Zhou L, Wu J. Development and application of medicinal plant tissue cultures for production of drugs and herbal medicinal in China. Nat Prod Rep 2006;23:789-10.

11. Kumar S, Upadhyay R, Aharwal RP, Sandhu SS. Antibacterial activity of some isolated endophytic fungi from Menthe viridis. Int J Appl Biol Pharm Technol 2016;7:239-8.

12. Singh RK, Singh A, Rath S, Ramamurthy A. A review of sarpagandha whole herb V/S reserpine-ITS alkaloid in the management of hypertension. Int Ayurvedic Med J 2015;3:565-9.

13. Petrini 0 . Taxonomic of endophytic fungi of aerial plant tissue. In microbiology of phylosphere. Cambridge: Cambridge University Press; 1986. p. 175-87.

14. Suryanarayanan TS, Venkatesan G, Murali TS. Endophytic fungal communities in leaves of tropical forest trees: Diversity and distribution patterns. Curr Sci 2003;85:489-2.

15. Photita W, Lumyong S, Lumyong P, Hyde KD. Endophytic fungi of wild banana (Musa acuminata) at dosi suthep pui National Park, Thailand. Asian Mycol Congress 2000;105:1508-3.

16. Aggarwal GP, Hasija SK. Microorganisms in the laboratory. In: Laboratory guide of mycology, Microbiology and plant pathology. Ravi printers Jabalpur, M. P. India; 1980. p. 58.

17. Sandhu SS. Recombinant DNA technology. I. K. International Publishing house Pvt. Ltd. New Delhi India; 2010.

18. Thompson JD, Gibson TJ, Plewniak F, Jeanmougin F, Higgins DG The CLUSTAL_X windows interface: flexible strategies for multiple sequence alignment aided by quality analysis tools. Nucleic Acids Res 1997;24:4876-2.
19. Kumar DSS, Hyde KD. Biodiversity and tissue-recurrence of endophytic fungi in Tripterygium wilfordii. Fungal Diver 2004;17:69-90.

20. Sandhu SS, Kumar S, Aharwal RP, Chaturvedi S. Antibacterial potential of endophytic fungi isolated from Saraca indica. J Biol Chem Sci 2014;1:24-34.

21. Newyork NY, Barnett HL, Hunter BB. Illustrated genera of imperfect fungi, Burgers Company, Minneapolis; 1972.

22. Shekhawat KK, Rao DV, Batra A. In vitro antimicrobial activities of endophytic fungi isolates from medicinal tree-Melia azadirachta L. J Microbiol Res 2013;3:19-24.

23. Sandhu SS, Kumar S, Aharwal RP. Isolation and identification of endophytic fungi from Ricinus Communis L. and their antibacterial activity. Int J Res Pharm Chem 2014;4:611-8.

24. Strobel G, Hess WM, Ford EJ, Sidhu RS, Yang X. Taxol from fungal endophytes and the issue of biodiversity. J Indian Microbiol 1996;17:417-3.

25. Kour A, Shawl AS, Rehman S, Sultan P, Qazi PH, Suden P, et al. Isolation and identification of an endophytic strain of Fusarium oxysporum producing podophyllotoxin from Juniperus recurva. World J Microbiol Biotechnol 2008;24:1115-1.

26. Silva DM, Batista LR, Rezende EF, Maria HP, Sartori FD, Alves E. Identification of fungi of the genus Aspergillus section nigr using polyphasic taxonomy. Braz J Microbiol 2011;42:761-73.

27. Nyongesa BW, Okoth S, Ayugi V. Identification key for Aspergillus species isolated from maize and soil of Nandi county, Kenya. Adv Microbiol 2015;5:205-29.

\section{How to cite this article}

- $\quad$ Rajshree Sahu, Suneel Kumar, Ravindra Prasad Aharwal, Sardul Singh Sandhu. Antibacterial activity of isolated endophytic fungi from rauvolfia serpentina (L.) benth. EX kurz. Int J Pharm Pharm Sci 2016;8(11):38-42. 